\title{
LOS INTERESES COMPROMETIDOS EN EL DAÑO AMBIENTAL. COMENTARIO AL NUEVO PROCEDIMIENTO POR DAÑO AMBIENTAL DE LA LEY N² 20.600*
}

\author{
JORGE BERTRAND TISNÉ NIEMANN**
}

RESUMEN: El medio ambiente es un bien jurídico de naturaleza colectiva. En materia de daños ambientales existen variedad de intereses comprometidos puesto que su deterioro importa a un gran número de personas. Se analizará la Ley de Bases Generales del Medio Ambiente en función de los intereses que actualmente la norma tutela. Se harán presentes las consideraciones personales respecto del necesario reconocimiento que debe existir de las situaciones legitimantes activas obviadas por el legislador. Asimismo, será comentado el nuevo procedimiento por daño ambiental consagrado en la ley $\mathrm{N}^{\circ} 20.600$ a efectos de proponer que su estructura admite bajo sutiles modificaciones la participación de todos los interesados en un daño ambiental.

PALABRAS CLAVE: Medio ambiente - intereses supraindividuales daño ambiental - legitimación activa - procedimiento por daño ambiental

\section{THE INTERESTS INVOLVED IN THE ENVIRONMENTAL DAMAGE. COMMENTS TO THE NEW ENVIRONMENTAL DAMAGE PROCEDURE IN LAW $\mathbf{N}^{\circ} \mathbf{2 0 . 6 0 0}$}

ABSTRACT: The environment as a legal right has a collective nature. An environmental damage involves variety of interests because its deterioration matters to many people. The Environmental Framework Law will be analyzed based on the current interests that are actually protected. We will state our personal considerations regarding the necessity to recognize the plaintiff's standing situations obviated by the legislator. Likewise, we will also comment the new environmental damage procedure enshrined

Fecha de recepción: 17 de abril de 2013.

Fecha de aceptación: 3 de enero de 2014.

** Licenciado en Ciencias Jurídicas. Magíster en Investigación Jurídica. Candidato a Doctor en Derecho, todos en Universidad de los Andes. Dirección postal: Facultad de Derecho, Universidad de los Andes, Monseñor Álvaro de Portillo 12.455, Las Condes, Santiago, Chile. Correo electrónico: jbtisne@miuandes.cl-j_tisne@hotmail.com. 
in the Law $\mathrm{N}^{\circ} 20.600$ in order to propose that a subtle modification to its structure should allow the intervention of every interested in an environmental damage.

KEY WORDS: Environment - diffuse and collective interests - environmental damage - plaintiff's standing - environmental damage procedure

Sumario: Introducción. 1) Intereses comprometidos en el daño ambiental. 2) La relación entre intereses y el acceso a la justicia. 3) Legitimación activa en la Ley de Bases Generales del Medio Ambiente (LBGMA). (3.1.) Las personas. (3.2.) Las municipalidades. (3.3.) El Estado. 4) Necesidad de reconocimiento legal de los intereses y de nuevos legitimados activos. 5) Comentarios al nuevo procedimiento por daño ambiental contenido en la Ley $N^{\circ}$ 20.600. Conclusiones. Bibliografía

\section{INTRODUCCIÓN}

La tendencia histórica ha sido concebir el proceso civil bajo el estricto velo de la individualidad del derecho subjetivo. Los conflictos entre particulares debían ser resueltos bajo el modelo clásico del derecho procesal civil. Los litigios se concebían necesariamente entre partes individuales, debidamente identificadas y representadas, que exponían los hechos y el derecho del caso concreto a un tercero imparcial, quien en función de la jurisdicción que ejercía, decidiría sobre el asunto sometido a su conocimiento.

Sin perjuicio de su efectividad, los estrictos modelos procesales han sido superados por las nuevas realidades. En este sentido, "la lógica individual decimonónica que inspira a todo el derecho civil y, en el caso que ahora interesa, a la regulación de la responsabilidad por el daño que generan los hechos ilícitos, no contempla la situación de daños que están más allá de los intereses de las personas individualmente consideradas" 1 . Actualmente, tanto el individuo como los nuevos cuerpos sociales exigen tutela de sus intereses ${ }^{2}$.

\footnotetext{
1 Brañes, Raúl (2000) Manual de derecho ambiental mexicano. 2a ed. México, D. F.: Fundación Mexicana para la Educación Ambiental Fondo de Cultura Económica, p. 284.

2 Para una referencia histórica del surgimiento de los intereses recomendamos Moreno, Pablo (2002) El interés de grupo como interés tutelado. Bogotá: Universidad Externado de Colombia, pp. 43-50; También PÉrez, Lorenzo (2002) La tutela judicial de los intereses ambientales (Estudio especifico de la legitimación $<<$ difusa $>>$ en el proceso contencioso-administrativo). Valladolid: Editorial Lex Nova, pp. 58-60.
} 
Con posterioridad a los acontecimientos de principios del siglo XX, florecieron las Constituciones y Tratados Internacionales garantistas de los derechos humanos. En un rápido proceso evolutivo, nuevos derechos alcanzaron rango constitucional, los denominados de tercera generación. Responden a expectativas colectivas para dar tutela a una nueva esfera de necesidades colectivas y no meramente privadas, donde la solidaridad juega un rol cardinal por ser intereses cuya satisfacción compromete a todos por igual ${ }^{3}$. Estos intereses comparten una naturaleza intrínsecamente colectiva, en donde su inobservancia genera necesariamente la afectación de los intereses de un grupo de compleja determinación. Aquellos comprometidos en función de un daño, entonces, deben entenderse supraindividuales, a diferencia de la concepción individualista tradicional del Derecho. Resulta imprescindible un conspicuo estudio de ellos con el objeto de adaptar las actuales instituciones procesales en materia ambiental.

Es menester distinguir tres tipos de intereses. El difuso, caracterizado por ser difícil o imposible la determinación del grupo afectado. El interés colectivo es aquel en que los integrantes del grupo son determinados o fácilmente determinables. Por último, destacan los intereses individuales homogéneos o plurisubjetivos definidos como aquellos que tienen naturaleza privada pero que accidentalmente se encuentran ligados por un hecho.

Tanto difusos como colectivos tienen un objeto indivisible por lo que se les considera supraindividual ${ }^{4}$. Aguirrezabal señala que "un derecho o interés sea supraindividual significa que trasciende la esfera de lo meramente individual, está marcado por la impersonalidad y rompe con el concepto clásico de derecho subjetivo" 5 . Los individuales homogéneos reciben una tutela procesal conjunta en función de la relación que existe en sus causas de pedir ${ }^{6}$.

3 A modo de ejemplo: protección del consumidor, derecho a vivir en un medio ambiente libre de contaminación, derecho a la paz, protección de niños y ancianos, derecho a la identidad nacional y el derecho a la no discriminación.

4 El autor Pérez (2002) 79 reafirma que la diferencia radica en la determinación del grupo. Dispone que en el caso de los intereses colectivos y difusos "nos encontramos ante un grupo de personas que están de manera común y simultánea en una misma situación jurídica con respecto a un bien que todos los individuos integrantes del grupo disfrutan conjunta y solidariamente y con relación al cual experimentan una necesidad común. Ahora bien, dicho sujeto grupal puede tratarse de una comunidad de personas determinada o fácilmente determinable en cuanto a sus miembros, o bien puede ser un masa social indeterminada o difícilmente determinable en lo relativo a sus componentes: en el primer caso, nos hallaríamos ante intereses colectivos, mientras que en el segundo estaríamos ante intereses difusos [...]".

5 Aguirrezabal, Maite (2006) "Algunas precisiones en torno a los intereses supraindividuales (colectivos y difusos)". Revista Chilena de Derecho, Vol. 33 N$^{\circ} 1$, p. 74.

6 Aguirrezabal, Maite (2006). "El procedimiento para la defensa de intereses colectivos y difusos de consumidores y usuarios en la Ley 19.496". Cuadernos de Extensión Jurídica (U. de los Andes), No 12, pp. 149-150. 
Estos intereses en el ámbito procesal tienden a ser observados como nuevos supuestos de situaciones jurídico-legitimantes y, por consiguiente, deben tener un derecho de acción autónomo distinto al del particular individualmente considerado. Dicho derecho se incoará materialmente en sede jurisdiccional mediante una acción colectiva que se define como "la acción propuesta por un representante (legitimación) en la defensa de un derecho colectivamente considerado (objeto del proceso) cuya inmutabilidad en la autoridad de la sentencia alcanzará a un grupo de personas (cosa juzgada). En una acción colectiva los derechos del grupo son representados en juicio por un representante y la sentencia será respecto a toda la controversia colectiva, alcanzando a los miembros titulares del derecho del grupo"7.

En el presente trabajo analizaremos las características del daño ambiental y los intereses que su acaecimiento involucra. Asimismo, en función de la legitimación procesal, analizaremos la Ley de Bases Generales del Medio Ambiente para determinar qué intereses son legalmente reconocidos y cuáles son los mecanismos previstos para otorgarles una tutela efectiva. Finalmente comentaremos el nuevo procedimiento por daño ambiental de la ley $\mathrm{N}^{\circ} 20.600$ pues, sutiles modificaciones legales admitirían a nuestro juicio, un tratamiento conjunto de los diversos intereses comprometidos en materia ambiental. Esto permitiría soslayar las dificultades procesales asociadas a la acreditación del daño y por consiguiente, estimular la accionabilidad ambiental y desincentivar, a la vez, la transgresión del entorno.

\section{1) INTERESES COMPROMETIDOS EN EL DAŃO AMBIENTAL}

El daño es un concepto trascendente en el ordenamiento ambiental de nuestro país. Conforme al artículo 2 letra e de la ley Número 19.300, este se define en los siguientes términos: Toda pérdida, disminución, detrimento o menoscabo significativo inferido al medio ambiente o a uno o más de sus componentes. El hecho que el daño deba ser calificable de significativo constituye una exigencia mayor para su acreditación ${ }^{8}$. El medio ambiente

7 Gidi, Antonio (2003). "El concepto de acción colectiva”. En Gidi, Antonio y Ferrer MacGregor, Eduardo (editores). La tutela de los derechos difusos, colectivos e individuales homogéneos. Hacia un Código Modelo para Iberoamérica. México: Editorial Porrúa, p. 15.

$8 \quad$ El autor Corral, Hernán (1996). "Daño ambiental y responsabilidad civil del empresario en la Ley de Bases Generales del Medio Ambiente”. Revista Chilena de Derecho, Vol. 23 N $^{\circ}$ 1, pp. 165-166 analiza el concepto. Nosotros en Tisné Niemann, Jorge Bertrand (2010) Acción de reparación Ambiental. Aspectos procesales relevantes. Tesis para optar al grado de Licenciado en Derecho. Universidad de los Andes, p. 19-24 ya hemos hecho presente nuestras consideraciones y un análisis jurisprudencial al respecto. 
será objeto de protección cuando la entidad del daño sea considerada de importancia o relevancia.

Esto es una importante distinción con la concepción civilista de dańo que tradicionalmente ha sido definida como "todo detrimento, perjuicio, menoscabo, dolor o molestia que sufre un individuo en su persona, bienes, libertad, honor, crédito, afectos, creencias, etc. El daño supone la destrucción o disminución, por insignificante que sea, de las ventajas o beneficios patrimoniales o extrapatrimoniales de que goza un individuo"?. Por lo tanto, es importante distinguir que en la materia en estudio, no todo daño será objeto de indemnización o reparación, sino solo el que ostente la calidad de significativo ${ }^{10}$.

Es por esto que el sistema de responsabilidad extracontractual del Código Civil es inadecuado para regular un daño ambiental pues su acaecimiento presenta características inherentes ${ }^{11}$. Su producción pone en movimiento una serie de mecanismos tendientes, entre otros objetivos, a su cesación y reparación.

Autores $^{12}$ y los tribunales de justicia ${ }^{13}$ han admitido que el medio ambiente no es un bien jurídico meramente individual sino que radical-

Alessandri, Arturo (2005) De la responsabilidad extracontractual en el derecho civil chileno. Santiago: Editorial Jurídica de Chile, p. 153.

10 El autor Barros, Enrique (2006) Tratado de responsabilidad extracontractual. Santiago: Editorial Jurídica de Chile, p. 788 señala que la entidad del daño importa porque "como ocurre con todos los bienes que se encuentran en situación de concurrencia recíproca, la protección al medio ambiente supone una ponderación relativa de los bienes afectados. La pretensión de una sociedad no es eliminar toda contaminación ambiental, sino fijar un nivel aceptable que se acerque a un equilibrio razonable de los bienes en juego [...] La reducción de la contaminación supone costos sociales, en los cuales solo se justifica incurrir en la medida que a ellos vayan asociados mayores beneficios correlativos para la comunidad". Asimismo, afirma en Barros, Enrique (1998). "Responsabilidad civil en materia de medio ambiente". En Derecho del Medio Ambiente Congreso Internacional. Santiago: LexisNexis, p. 55 que el daño ambiental tiene un "[...] carácter genérico u holístico que se resiste a la definición precisa de sus límites [...] pero el daño ambiental contiene un elemento normativo que obliga a discriminar: la pérdida disminución, detrimento o menoscabo debe ser significativo para que de lugar a daño indemnizable o reparable. Esta calificación obliga a distinguir entre aquello que es una molestia que debe ser soportada como condición general de la vida en común, de lo que es propiamente un dańo indemnizable" o reparable.

11 En el mismo sentido Brañes (2000) 284-285.

12 El autor Pérez (2002) 102-103 sostiene que es colectivo pues su goce y disfrute interesa a todas las personas por igual.

13 Así lo ha entendido la Corte Suprema (Corte Suprema. 23 de septiembre de 1997. Rol No 654-1997. "Stutzin Schottlander, Miguel y otros c/ Comisión Regional del Medio Ambiente de la X Región”. Microjuris. Cita MJCH_MJJ1381, p. 6) al señalar en el considerando decimotercero de la referida sentencia que "[...] cabe señalar desde ya que el derecho de vivir en un medio ambiente libre de contaminación es un derecho humano fundamental, con rango constitucional, derecho que presenta un doble carácter: derecho subjetivo público y derecho colectivo público. El primero de éstos se caracteriza porque su ejercicio corresponde, como lo señala el artículo 19 de la Constitución Política de la República, a todas las personas, debiendo ser protegido y amparado por la autoridad a través de los recursos ordinarios que correspondan, como asimismo a través del recurso de protección. Y, en lo que 
mente colectivo. Su deterioro compromete los intereses de todos aquellos que pretenden un medio ambiente libre de contaminación, tal como prescribe la Carta Fundamental en el artículo 19 número 8, fuente del derecho subjetivo ambiental. Toda persona revela una esfera de intereses ambientales susceptible de tutela. El daño individual pierde su concepción clásica en la materia, pudiendo existir intereses de reparación aun cuando materialmente no se haya afectado directamente al particular ${ }^{14}$.

El interés es identificable con una legítima expectativa a que el ambiente permanezca en calidades, niveles, concentraciones y estándares que permitan a cada uno de los integrantes de la nación disfrutar y beneficiarse de un medio ecológico apto para las necesidades presentes y futuras. Es importante entender que son los miembros de la colectividad heterogénea que en su conjunto ostentan una legítima necesidad impersonal de velar por un medio ambiente adecuado ${ }^{15}$.

En un primer acercamiento, podemos concluir que efectivamente el interés difuso se encuentra comprometido en materia ambiental. El cuerpo de individuos indeterminados del país manifiesta una legítima expectativa respecto de un bien de naturaleza colectiva, como es el de vivir

dice relación con el segundo carácter del derecho en análisis, es decir, el derecho colectivo público, él está destinado a proteger y amparar derechos sociales de carácter colectivo, cuyo resguardo interesa a la comunidad toda, tanto en el plano local como en el nivel nacional, es decir, a todo el país, ello por cuanto se comprometen las bases de la existencia como sociedad y nación, ya que al dañarse o limitarse el medio ambiente y los recursos naturales, obviamente se limitan las posibilidades de vida y desarrollo no solo de las actuales generaciones, sino también de las futuras. En este sentido, su resguardo interesa a la colectividad toda, ello por afectar a una pluralidad de sujetos que se encuentran en una misma situación de hecho, y cuya lesión, pese a ser portadora de un gran daño social, no les causa un daño significativo o apreciable claramente en su esfera individual".

14 En Silva, Hernán (1993). "La protección del ambiente en el derecho constitucional y penal". Revista Chilena de Derecho, Vol. 20 N²-3, p. 677 el autor dispone que "el medio ambiente es un bien jurídico que le corresponde a todas las personas para ser gozado y disfrutado en forma racional. Es un bien o valor jurídico de tipo supraindividual, de carácter macrosocial o colectivo, es patrimonio de la nación entera”.

15 El interés supraindividual se explica en función de la estrecha relación entre particulares individualmente considerados, titulares de posiciones subjetivas exclusivas, y el interés de la colectividad en cuanto miembros de la comunidad. El interés supraindividual no es una realidad substancialmente objetiva. Gutiérrez de Cabiedes e Hidalgo de Caviedes, Pablo (1999) La tutela jurisdiccional de los intereses supraindividuales: colectivos y difusos. Navarra: Editorial Arazandi, pp. 77-80.

Sin embargo hacemos presente que este no es un punto pacífico en la doctrina. Gidi, Antonio (2003). "Derechos difusos, colectivos e individuales homogéneos". En Gidi, Antonio y Ferrer Mac-Gregor, Eduardo (editores). La tutela de los derechos difusos, colectivos e individuales homogéneos. Hacia un Código Modelo para Iberoamérica. México: Editorial Porrúa, p. 30 señala que "al contrario de lo que se acostumbra a afirmar, no son muchos, ni indeterminados, los titulares (sujetos de derecho) de los derechos difusos, colectivos o individuales homogéneos. Solo tiene un único titular y muy bien determinado: una comunidad en caso de derechos difusos, una colectividad en el caso de derechos colectivos o una serie de victimas indivisibles en el caso de los derechos individuales homogéneos". 
en un medio ambiente libre de contaminación ${ }^{16}$. En este sentido, es indudable que un daño ecológico conforme al ordenamiento nacional compromete el interés difuso ambiental. De hecho, las singularidades un daño en la materia podrían implicar que sus consecuencias afecten incluso a generaciones futuras, aún no nacidas, que eventualmente requerirán del medio ambiente para su posterior desarrollo. La trascendencia que implica este rasgo único del daño ambiental, en contraposición a otros propios de la esfera individual, permite de forma cierta y reveladora demostrar el carácter difuso. Aun cuando del daño se derive perjuicio a cada uno de los miembros de una colectividad, nunca se podrá tener certeza de la amplitud real de generaciones conculcadas. La impersonalidad del grupo es un elemento del interés difuso ambiental que brota de forma natural, encontrando fundamento a la luz de la solidaridad y de las necesidades mancomunadas.

Teniendo presente la existencia del interés difuso, es dable considerar la existencia de aquel de carácter colectivo, definido como "[...] de naturaleza supraindividual e indivisible, pero entre los titulares de esos intereses existe algún tipo de vinculación jurídica" ${ }^{17}$. Si la esfera de intereses ambientales puede ser radicada en un grupo indeterminado de personas, también será oportuno identificar un interés colectivo en un grupo determinado de personas que tienen un interés por tutelar un medio ambiente diligentemente cuidado. En este sentido, nada obsta que el universo de afectados pueda ser subdividido en grupos más reducidos o acotados, debidamente representados, y que constituyan un cuerpo concreto e identificable ${ }^{18}$.

Por lo tanto, imprescindible resulta considerar que el interés ambiental que se manifieste ante un daño, no es ni debe ser objeto exclusivo del ejercicio particular de un único cuerpo social. Las características propias de su naturaleza colectiva, permite la existencia de diversos organismos o agentes colectivos, tendientes a la obtención de un fin único, esto es, la tutela ambiental. La política legislativa de cada país ponderará la estructura y cantidad de entes con capacidad para representar y tender a la protección jurisdiccional de los intereses ${ }^{19}$.

16 A pesar que el autor confunda el interés colectivo y el interés difuso, es atingente el comentario de Garrido, Lidia (1993) Los daños colectivos y la reparación. Buenos Aires: Editorial Universidad, p. 183 cuando expone que "hoy, la comunidad enfrenta la pugna del reconocimiento del derecho de defensa de los intereses colectivos, como el aire sano, la calidad de vida adecuada, de todos los que conformamos el anónimo y desposeído ser de la masa social, que tenemos derecho a proteger nuestros intereses y ser oídos en justicia”. Aguirrezabal (2006) 150.

Comparte la existencia del interés difuso y colectivo en materia ambiental Brañes (2000) 284 pero lo identifica como un daño supraindividual en función del autor y los afectados por la transgresión ambiental.

19 En otros países, explica Bujosa, Lorenzo (1995) La protección jurisdiccional de los intereses de grupo. Barcelona: J.M. Bosch editor, pp. 224-292 se ha legitimado a diversos entes para la protección de intereses supraindividuales, tal como al Ministerio fiscal, el Defensor del 
Sin perjuicio de lo expuesto, el interés comprometido en razón de un daño ambiental no se agota en estructuras colectivas o sociales que encuentran el fundamento de su actuación en intereses ambientales supraindividuales. El individuo es relevante por ostentar una posición subjetiva exclusiva. De excluirlo, la esfera particular ambiental quedaría exenta de herramientas para su tutela. Cada una de las personas que sea afectada por un daño ambiental, dentro del orden se sus expectativas legítimas, debe estar facultada para velar por su esfera privada de derechos.

Conforme a la clasificación, ante un daño al entorno varias personas pueden estar afectas al perjuicio ambiental, siendo cada interés perfectamente individualizable y divisible, pero encontrándose inmanentemente unidos por un hecho particular. El objeto del interés es entonces compartido entre cada una de las personas individualmente consideradas, circunstancia que se puede definir como el interés individual homogéneo ambiental. El origen común de dichos intereses puede identificarse en la llamada causa de pedir del derecho procesal. No es necesario que sean idénticas. Lo relevante será identificar en el conjunto de causas de pedir un nicho sólido de intereses compartidos por el grupo, que constituirá el fundamente de la acción colectiva ${ }^{20}$.

\section{2) LA RELACIÓN ENTRE INTERESES Y EL ACCESO A LA JUSTICIA}

Los tres tipos de intereses previamente expuestos son complementarios y en ningún caso excluyentes ${ }^{21}$. Un mismo hecho puede generar la necesidad de tutela tanto del interés difuso, colectivo e individual homogéneo. La naturaleza de todos ellos es la misma, a saber, la protección del medio ambiente adecuado, sin perjuicio que cada cual proteja su propio ámbito de afectación. El mayor o menor grado de tutela exigible es direc-

Pueblo (Ombusdman), las asociaciones, acciones populares o acciones de grupo. Contribuye a esta idea BrAÑEs (2000) 286-291 quien da cuenta de la figura del Interventor Público y la Procuraduría del Medio Ambiente que son titulares de acciones ambientales. Los mecanismos procesales que el autor menciona para la tutela de los intereses supraindividuales son la acción civil pública brasileña de responsabilidad por daños causados al medio ambiente, las garantías constitucionales ambientales de las Cartas Fundamentales latinoamericanas, la denuncia popular y, particularmente en el derecho estadounidense, la injuction y la class action. Esta última tiene por finalidad que se interponga la acción judicial ambiental en representación de un interés colectivo o difuso sin que las personas interesadas estén individualizadas ni que hayan prestado su consentimiento para entablarla.

20 Gidi (2003) 36-37.

21 El autor GARRIDo (1993) 183 enfatiza que "se ha sostenido que la defensa del medio ambiente es el típico ejemplo de interés difuso o colectivo, diferenciándolo del de los consumidores como si estos fueran intereses de clase; lo cierto es que se caracterizan por pertenecer a una pluralidad de individuos de una manera 'desparramada', lo que no implica, como dijimos, que no puedan coexistir con un interés individual”. 
tamente proporcional al interés que se esgrima. No debe considerárseles por lo tanto como entidades diversas y sin conexión sino todo lo contrario.

Oportunas resultan las palabras de Valls al comentar "el interés ambiental suele estar repartido o diluido entre muchos y la vinculación entre el interés propio y ajeno es muy estrecha, por lo que cuando se defiende el interés propio se está defendiendo el ajeno y recíprocamente, por lo tanto, quien acciona en defensa del ambiente suele hacerlo también en defensa del bien ajeno, además del suyo propio. Pero el beneficio que la acción lleva a terceros no implica que falta interés propio" 22 . La necesaria y natural relación entre intereses propios y de la colectividad se explican a la luz del medio ambiente como bien tutelado. Ya hemos seńalado, que su naturaleza es colectiva porque toda la comunidad pretende su adecuada protección. La importancia de la clasificación recae principalmente en la manera de materializar el acceso a la justicia de los distintos tipos de intereses.

Ahora bien, la legitimación de los titulares de acciones colectivas responde a tres características: concurrente, disyuntiva y exclusiva ${ }^{23}$. En este sentido, la propia naturaleza de las acciones permite corroborar que los intereses no son excluyentes entre sí, incluso ante el accionar simultáneo de diversos legitimados activos, sino que complementarios ${ }^{24}$.

El medio ambiente es un bien jurídico colectivo pero el accionar individual tiende a ser mermado por dificultades de carácter fáctico, psicológico y cultural. Entre los primeros encontramos los largos tiempos de espera para obtener una resolución y los costos asociados para llevar adelante un proceso de esta naturaleza, especialmente considerando la dificultad para acreditar la responsabilidad y los costos de abogados y peritos altamente especializados que deberán intervenir en virtud de la complejidad de la materia. El carácter psicológico se explica porque muchas veces el daño individualmente considerado es insignificantivo o de poco valor por lo que demandarlo implica una carga que el interesado no siempre estará dispuesto a asumir. Además, el hecho de tener que litigar con empresas o agentes comerciales que ostentan un poder económico considera-

\footnotetext{
22 Valls, Mario (2001) Manual de Derecho Ambiental. Buenos Aires: Ugermer Editor, p. 238.

23 Gidi, Antonio (2003). "Legitimación para demandar en las acciones colectivas". En Gidi, Antonio y Ferrer Mac-Gregor, Eduardo (editores). La tutela de los derechos difusos, colectivos e individuales homogéneos. Hacia un Código Modelo para Iberoamérica. México: Editorial Porrúa, p. 110 expone en relación al Código Modelo para Procesos Colectivos para Iberoamérica que "la legitimación se dice concurrente porque la legitimación de una de las entidades no excluye la de la otra: son todas independientemente legitimadas para demandar en juicio. -También es llamada disyuntiva, ya que cualquiera de las entidades colegitimadas podrá proponer, por sí sola, la acción colectiva sin necesidad de la formación del litisconsorcio o de la autorización por parte del los demás colegitimados. Está permitido, sin embargo, la formación voluntaria del litisconsorcio.- Finalmente, se trata de una legitimación exclusiva porque solamente aquellas entidades específicamente previstas en el Código Modelo podrán proponer una acción colectiva”.

24 El autor Pérez (2002) 84 comulga con esta idea.
} 
blemente mayor al individuo, contribuye al desincentivo de la pretensión jurídica. Finalmente, el elemento cultural trasciende porque en un país de arraigada concepción legalista y judicial como el nuestro, la vía jurídica se presenta como el óptimo, y a veces, el único camino prudente para efectos de obtener una adecuada protección de los intereses y derechos ${ }^{25}$.

Es por esto que el acceso a la justicia de los intereses supraindividuales promueve la justiciabilidad de situaciones por las cuales normalmente una persona no entablaría una acción individual. En este sentido, el cúmulo de interesados permite soslayar las dificultades materiales y morales vinculadas a un juicio ${ }^{26}$.

En materia de legitimación, no es conveniente que los intereses supraindividuales se sujeten a la estructura procesal clásica pues impide una tutela idónea de las pretensiones de masas. Circunscribir los conflictos de intereses ambientales en las estructuras procesales tradicionales conlleva transformarlos "[...] en litigios subordinados exclusivamente a los intereses particulares, en circunstancias en que por lo general hay un interés social involucrado en ellos. [...] Por otra parte, de acuerdo con esta misma lógica, el conflicto jurídico generado queda enmarcado por las disposiciones procesales previstas para la composición de los litigios en los que están involucrados intereses individuales" 27.

Habiendo delimitado conceptos importantes para el presente trabajo, resulta menester conocer el sistema previsto por el ordenamiento nacional sectorial para tutelar los diversos intereses comprometidos en un daño ambiental y si dicha solución legislativa es coherente con la actual necesidad de tutela colectiva.

25 En ese mismo sentido Bordalí, Andrés (2004) Tutela jurisdiccional del medio ambiente. Santiago: Editorial Fallos del Mes, pp. 212-220; Bujosa (1995) 120-127; Verbic, Francisco (2007) Procesos Colectivos. Buenos Aires: Editorial Astrea, pp. 51-60; Cfr, Peña González, Carlos (1997). "Las acciones de interés público en el ordenamiento jurídico chileno. Antecedentes dogmáticos y conceptuales". En Felipe González Morales (editor). Cuadernos de análisis jurídico. Serie publicaciones especiales. Las acciones de interés público. Argentina, Chile, Colombia y Perú. Santiago: Escuela de Derecho Universidad Diego Portales, N 7, p. 371 agrega a estos problemas los altos costos de transacción, asimetrías de información, imposibilidad de igualdad de armas, estructuras de costas, la escasa defensa y reconocimiento de estos intereses por parte de la jurisprudencia, entre otros.

En el mismo sentido Aguirrezabal, Maite (2010). "El control de la representatividad adecuada de las asociaciones de consumidores en el ejercicio de las acciones colectivas". Revista de Derecho Universidad Austral de Chile. Vol. 23 N 2, p. 176 clarifica que "como consecuencia del surgimiento de los intereses supraindividuales, aparecen y se desarrollan cuerpos sociales intermedios que organizadamente pueden conseguir de modo más efectivo la satisfacción de intereses o la consecución de fines que el ciudadano no puede obtener de modo aislado, porque los obstáculos en el acceso a la justicia les afectan con menor intensidad, y gozan de una mayor disponibilidad frente a las exigencias de la tutela de estos intereses". Brañes (2000) 285. 


\section{3) Legitimación aCtiva eN la LeY de BaSes GeNerales Del MEDIO AMBIENTE (LBGMA)}

El artículo 54 de la LBGMA consagra taxativamente aquellos actores que pueden entablar la acción que tiene por única finalidad reparar el medio ambiente dañado. Pueden identificarse tres categorías de legitimados. La primera constituida por las personas naturales o jurídicas, de derecho público o privado que han sufrido el daño o perjuicio directamente. En segundo término, las municipalidades por los hechos acaecidos en sus respectivas comunas. Finalmente se concede derecho para accionar al Estado por intermedio del Consejo de Defensa del Estado.

Sin perjuicio de estos tres grupos, se establece la facultad para que cualquier persona requiera ante la municipalidad en cuyo ámbito se desarrollen las actividades que causen daño ambiental, para que esta en su representación y sobre la base de los antecedentes que el requirente deberá proporcionar, deduzca la respectiva acción ambiental.

La legitimación activa consagrada en la LBGMA es la respuesta que el legislador ha ofrecido para enfrentar un daño ambiental y para obtener la reparación del mismo. Sin perjuicio de la reciente reforma a la institucionalidad ambiental mediante las leyes $\mathrm{N}^{\circ} 20.417$ y $\mathrm{N}^{\circ} 20.600$, los legitimados activos para la acción ambiental no han variado, lo que a nuestro juicio redunda en una limitada actividad jurisdiccional ${ }^{28}$.

\section{1.) LAS PERSONAS}

Al señalar que las personas naturales o jurídicas, de derecho público o privado que han sufrido el dańo o perjuicio directamente puedan ejercer la acción ambiental es la consagración en materia ambiental de la visión decimonónica individualista del derecho.

Emana de la norma que a través de esta acción el titular no tendrá por objeto una indemnización personal del daño sufrido (lo que podrá obtener en función del artículo 53 inciso primero del mismo cuerpo legal) sino que únicamente la reparación del medio ambiente dańado. Expresamente la norma ha prevenido que la esfera de legítima expectativa ambiental de todo particular puede ser afectada por un daño y por lo tanto consagró la acción individual de reparación. Sin embargo debemos tener presente que al tratarse de un bien jurídico colectivo, el accionar individual tendrá un efecto mediato o reflejo en el interés supraindividual ${ }^{29}$.

\footnotetext{
28 En el mismo sentido Delgado, Verónica (2012) "La responsabilidad civil extracontractual por daño ambiental causado en la construcción u operación de las carreteras”. Revista de Derecho (Valdivia), Vol. $25 \mathrm{~N}^{\circ} 1$, p. 63.

29 En Bordalí (2004) 266-277 el autor comparte nuestra apreciación cuando sostiene que "[...] la legitimación activa individual es procedente para la tutela de los derechos e intere-
} 
En el mismo sentido se pronuncia Roca que admite que la persona tendrá legitimación para accionar por el entorno privado afectado por un dańo ambiental, se corre el riesgo que este interés quede subsumido o diluido en aquellos de la comunidad representados por órganos de mayor entidad que el individuo ${ }^{30}$.

Se presentan inquietudes lógicas. ¿Qué ámbito de ejercicio tiene el individuo respecto del interés ambiental?, ¿hasta qué punto se puede considerar al particular como garante de medio ambiente? y por último ¿podrían las personas intentar una acción de reparación aludiendo un interés supraindividual que supere al meramente personal? A nuestro juicio, y en consideración de la norma actual, un particular solo podrá accionar por el propio daño sufrido. El ámbito de protección que le compete es el estrictamente personal y no tiene posibilidad de impetrar una acción en función de un interés mayor que el meramente privado pues no comparte la naturaleza indivisible del interés supraindividual ${ }^{31}$.

La norma es expresa al exigir que la persona sea directamente afecta$d a$. No es arbitraria su redacción toda vez que dicho calificativo impone un límite a la legitimidad personal. Esto no significa que en un daño ambiental el único universo de intereses comprometidos de carácter individual sean aquellos de los individuos legitimados. Simplemente aquellos que no hayan sido directamente afectados se les impide accionar, no por falta de interés, sino por no contar con legitimación activa. Es la manera que el legislador escogió para reconocer el interés particular relevante en materia de daño ambiental en desmedro de los demás interesados individuales. A mayor abundamiento, de la historia de la LBGMA $^{32}$ se observa el trámite legislativo en que expresamente se rechazó la enmienda que proponía el concepto interés en reemplazo del directamente afectado. La razón del Senado de impedir la redacción de la norma en dicho término

ses colectivos ambientales. En efecto, tanto el derecho fundamental como el interés legítimo en relación al bien ambiente son situaciones subjetivas individuales aunque exista una proyección o dimensión colectiva en ellos. Sin embargo, lo colectivo de este derecho no tiene por qué negar la posibilidad de una defensa del propio particular".

30 Cfr, Roca Juan, Juan (1986): "Sobre el deber general de respeto a la persona (derecho civil

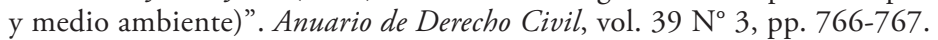

31 En el mismo sentido Gidi (2003). 110 señala que "en el Derecho brasileño, las personas físicas y las demás personas jurídicas no tienen legitimación para proponer acciones colectivas, excepto en estrictos casos de acción popular”.

32 El día martes 25 de enero de 1994, en la sesión 29a , el Senado, en tercer trámite, rechazó la modificación hecha por la Cámara de Diputados en el primer informe del segundo trámite constitucional, respecto del primer inciso que contenía la disposición en comento (en ese entonces artículo 57, actual artículo 54) porque la enmienda propuesta señalaba que serían titulares de la acción las personas naturales o jurídicas, públicas o privadas que tuvieran interés en ello[...], lo que fue respaldado por el Ejecutivo ante Comisión Mixta y luego por la misma Comisión, consagrando la norma bajo la redacción que hoy prescribe la ley. ToLedo, Fernando (1996) Ley sobre Bases Generales del Medio Ambiente: Ley Número 19.300, historia fidedigna y concordancias internas. Santiago: CONAMA, p. 191. 
fue que "abre la norma a una interpretación extensiva que no se corresponde con el criterio de acotar el ámbito de quienes pueden ser considerados titulares de la acción ambiental" 33 .

De este modo podemos reafirmar que el legislador no estimó conveniente que un particular ejerciera la acción en base a un interés mayor que el meramente privado. Estimamos que si bien es difícil auspiciar un aumento de demandas ambientales al ampliar la legitimación, el hecho de ofrecer esta posibilidad al menos no implica un desincentivo o un detrimento de las posiciones legitimantes actuales de la acción en comento ${ }^{34}$.

Por último es importante seńalar que la clasificación de intereses individuales homogéneos es perfectamente aplicable a la materia ambiental, toda vez que al tener por objeto la reparación del ambiente, si bien los particulares son individualizables, su pretensión se origina en el mismo hecho (daño). En este sentido, un proceso que los agrupe en una única demanda será imprescindible para evitar pluralidad de juicios y sentencias contradictorias.

\section{2.) LAS MUNICIPALIDADES}

Las municipalidades podrán accionar cuando el daño acaezca en su comuna o a petición de interesados conforme al artículo 54 de la LBGMA. Sin perjuicio de todas las inquietudes que nos genera la redacción de la norma ${ }^{35}$, entendemos que las municipalidades siempre accionan en nombre propio, independiente de la vía que origine su actuación.

En el primer supuesto, accionar de oficio responde a una intención particular del municipio por lo que estimamos que ahondar en su análisis resulta improductivo. El supuesto de accionar a solicitud de interesado ${ }^{36}$ puede ser objeto de un análisis más acabado.

33 Toledo, Fernando (1996) 191.

34 Siempre y cuando sea reformada la norma 54 de la LBGMA en cuanto dispone que los demás interesados deben intervenir en un litigio ambiental ya iniciado con la calidad de tercero coadyuvantes. Bajo esta perspectiva, incrementar el abanico de legitimantes sí tendría efectos perversos toda vez que se monopolizarían con aún más facilidad juicios que, teniendo injerencia para la sociedad toda, podrían ser terminados, perdidos u objeto de transacciones económicas por la parte demandante en desmedro de los intereses de la colectividad. Delgado (2012) 64 también considera errónea la restricción de exigir que terceros intervengan como coadyuvantes. A mayor abundamiento compartimos con Bordalí (2004) 277 - 282 quien considera inconstitucional dicha norma pues afecta el acceso a la justicia y el derecho de acción de un nuevo interesado.

35 Ver TISNÉ (2010) 58-64.

36 El inciso segundo del artículo 54 de la LBGMA dispone que cualquier persona podrá requerir a la municipalidad en cuyo ámbito se desarrollen las actividades que causen daño al medio ambiente para que esta, en su representación y sobre la base de los antecedentes que el requirente deberá proporcionarle, deduzca la respectiva acción ambiental. La municipalidad demandará en el término de 45 dias, y si resolviere no hacerlo, emitirá dentro de igual plazo una resolución fundada que se notificará al requirente por carta certificada. La falta de pronunciamiento de la 
Es importante destacar que existe una inconsistencia cuando la norma dispone que la municipalidad accionará en representación del interesado. La municipalidad no actuará en representación de la parte interesada, sino mediante una legitimación extraordinaria por substitución procesal. Romero aclara que "la sustitución es una figura distinta de la representación procesal. Como se sabe, la representación se caracteriza por la actuación que un tercero realiza en nombre de otro en un proceso. Cualquiera sea la clase de representación, lo distintivo es que el representante actúe en nombre ajeno y por un derecho igualmente ajeno, a diferencia de la sustitución, donde el sustituto actúa en su nombre, adquiriendo él la calidad de parte" 37 .

En definitiva, la municipalidad no representará a ningún interesado, sino que entablará la acción en nombre propio, asumiendo la calidad de parte en el proceso y ejerciendo una legitimación activa propia. Es improcedente sostener que ejerce una acción colectiva en representación de aquellos que aportaron los antecedentes del caso ${ }^{38}$.

La actuación por parte de la municipalidad no ha sido pensada como un instrumento para canalizar pretensiones ambientales de la colectividad. La Ley $\mathrm{N}^{\circ} 19.300$ al señalar expresamente que la solicitud de interesado se podrá hacer únicamente en la municipalidad en cuyo ámbito se desarrollen las actividades que causen daño al medio ambiente ha establecido un límite a la legitimación. La restricción funciona igual que la exigencia de directamente afectado que se exige para que el particular pueda accionar. En este sentido, no cualquier municipalidad puede accionar a solicitud de un grupo de personas determinadas cuyos intereses han sido comprometidos por un daño ambiental. Solo aquella en donde se haya producido el perjuicio podrá ser requerida para que oponga judicialmente la pretensión. Por lo tanto, esta es otra razón para confirmar que el legislador no ha querido que los municipios sean órganos que representen intereses colectivos, de lo contrario, lo lógico sería pensar que ante un daño ambiental los interesados pudieran recurrir a su propia municipalidad para que esta, en función de las expectativas de reparación de un grupo determinado de personas, ejerza la acción en su representación.

municipalidad en el término indicado la hará solidariamente responsable de los perjuicios que el hecho denunciado ocasionare al afectado.

37 Romero, Alejandro. (2006) Curso de derecho procesal civil. La acción y la protección de los derechos. Santiago: Editorial jurídica de Chile. t. I, p. 100.

38 El autor Delgado (2012) 64 también critica la norma al señalar que “[...] podría pensarse que existe una especie de 'acción popular' ella no es más que una simple petición, que no hace al solicitante parte en el juicio y que podrá generar, a lo más, responsabilidad solidaria de la Municipalidad, respecto a los daños personales del peticionario (y no al daño ambiental puro), siempre y cuando además se cumplan varias condiciones”. 
A mayor abundamiento, el artículo 18 de la Ley $\mathrm{N}^{\circ} 20.600^{39}$ que crea los Tribunales Ambientales, ratifica expresamente en su numeral segundo que en materia de reparación ambiental, podrán participar como parte en juicio las municipalidades por los hechos acaecidos en sus respectivas comunas. No hace siquiera mención a la posibilidad de accionar en representación de los solicitantes. Claramente el legislador no ha considerado a la municipalidad como representante de intereses colectivos.

Cualquiera sea el mecanismo que lleve al municipio a accionar ambientalmente (oficio o a solicitud de interesado), lo cierto es que siempre estaremos ante un interés individual del ente administrativo. Si bien la clásica concepción de interés particular dice relación con las personas, las municipalidades accionan en nombre propio y no en representación de un grupo determinado o indeterminado de personas.

\section{3.) El ESTADO}

Finalmente, el Estado mediante el Consejo de Defensa del Estado es el último legitimado activo para ejercer la acción ambiental. No se describen los supuestos de hechos por los cuales el Estado puede demandar por lo que se entiende que lo podrá hacer "[...] ante cualquier hipótesis de daño ambiental, cualquiera sea el lugar del territorio o zona sometida a la jurisdicción nacional donde este se produzca" ${ }^{40}$.

La designación del Consejo de Defensa del Estado para incoar el proceso jurisdiccional por daños ambientales ha sido objeto de críticas por un sector de la doctrina nacional. Estas dicen relación con que dicho ente público no es un adecuado representante de los intereses y derechos de la comunidad porque el medio ambiente es un bien jurídico colectivo y no un bien público estatal. El órgano que se designe para defender el interés difuso comprometido por un daño ambiental debe accionar siempre que corresponda sin estar sometido a presiones externas. El Consejo de Defensa del Estado es dependiente del Poder Ejecutivo y tiene por objeto la defensa de los intereses del Estado. Su capacidad para demandar queda cuestionada cuando la Administración considere inadecuado, por

39 Dispone el artículo 18 que podrán intervenir como partes en los asuntos de competencia de los Tribunales Ambientales las personas naturales o jurídicas que hayan sufrido el daño o perjuicio; las municipalidades, por los hechos acaecidos en sus respectivas comunas, y el Estado, por intermedio del Consejo de Defensa del Estado. Deducida demanda por alguno de los titulares señalados no podrán interponerla los restantes, lo que no obsta a su derecho a intervenir como terceros coadyuvantes. En el caso del inciso quinto del artículo 43 de la Ley Orgánica de la Superintendencia del Medio Ambiente, la acción deberá siempre ejercerla el Consejo de Defensa del Estado como parte principal.

40 Valenzuela, Rafael (1998). "La Responsabilidad Civil por Daño Ambiental". En Derecho Del Medio Ambiente Congreso Internacional. Santiago: LexisNexis, p. 67. 
cualquier razón, solicitar la reparación de un daño ambiental o este sea producto de la actividad de los órganos dependientes del poder público ${ }^{41}$.

En definitiva el Consejo de defensa del Estado entablará la acción ambiental cuando se encuentre comprometido únicamente el propio interés del Estado. No se debe confundir el interés público o general con los intereses supraindividuales y los intereses del Estado.

El interés público o general es aquel que envuelve al mayor número de personas. Dice relación con el interés que puede generar un hecho particular en cualquier integrante de la comunidad nacional ${ }^{42}$. En este sentido, el interés difuso se subsume dentro de este. No es necesario individualizar un grupo, incluso de difícil determinación, pues el interés corresponde a cualquiera. Luego, incluso en el difuso existirán personas cuyos intereses no se hayan comprometido; no así en el público o general $^{43}$. De este último, derivan las acciones públicas o populares. Los casos de acciones populares en Chile no son comunes pero nos parece oportuno mencionar a modo de ejemplo aquellas contempladas en los artículos $948^{44}, 2.328^{45}$ inciso segundo y $2.333^{46}$ del Código Civil. Dejamos cons-

\section{BORdALÍ (2004) 297-298.}

42 En Tisné Niemann, Jorge (2012). "Algunas particularidades en torno al derecho de acción ambiental en la ley número 20.600". Revista de Derecho de la Universidad de Concepción, Vol. $80 \mathrm{~N}^{\circ}$ 231-232, p. 118 nos hemos pronunciado en el mismo sentido en ocasión al comentario a la figura del Amicus Curia prevista en la ley $\mathrm{N}^{\circ} 20.600$.

43 Hacemos presente que PeÑa (1997) p. 367 ha definido el interés público en términos que no compartimos pues lo identifica con aquellos que se pueden imputar directamente al Estado u órganos que lo representen. Nosotros sostenemos que dicho interés no solo compromete al Estado sino a todo aquel que forme parte de la comunidad nacional. Asimismo, el interés difuso lo entiende en términos económicos, esto es, como las externalidades negativas de una actividad. Tampoco compartimos este planteamiento porque lo hemos explicado en función de la indivisibilidad del objeto y la dificultad de determinación del grupo.

44 En Amunátegui Pereló, Carlos Felipe (2012). "Las relaciones de vecindad y la teoría de las inmisiones en el Código Civil". Revista de Derecho de la Pontificia Universidad Católica de Valparaíso, Vol. $38 \mathrm{~N}^{\circ}$ 1, p. 115 al referirse al artículo 948 del Código Civil admite que "llama la atención, sin embargo, el escaso interés que ha suscitado tal disposición en la dogmática nacional, que generalmente la ignora, así como su pésima interpretación en algún fallo que rechaza aplicarla" pues el autor estima que su aplicación admite una nueva esfera de tutela ambiental. En el mismo sentido ver Delgado Schneider, Verónica Pía (2005). "La protección del medio ambiente a través de las acciones populares del artículo 948 del Código Civil de Andrés Bello: un estudio histórico-comparativo". En María Dora Martinic G., y Mauricio Tapia R. (dirección), Sesquicentenario del Código Civil de Andrés Bello. Pasado, presente y futuro de la codificación. Santiago: LexisNexis, t. II, pp. 907-937.

45 Así lo reiteran últimamente González Cruz, Francisco Javier y Acevedo Ferrer, Santiago (2013). "Revisión crítica del estatuto de responsabilidad civil por daños nucleares en Chile". En Revista Chilena de Derecho, Vol. 40 N 1, p. 37 al señalar que "[...] la acción popular del artículo 2328 del Código Civil tiene la grave limitación de su redacción, que la circunscribe a cosas ubicadas en la parte superior de un edificio que amenacen caída y daño".

46 Esta acción ha sido considerada por parte de la doctrina como posible complemento a la ley $\mathrm{N}^{\circ} 19.300$ pues no requiere del dańo consumado sino que responde a una tutela preventiva del dańo contingente. En este sentido Diez Schwerter, José Luis (2005). "Notas sobre la acción preventiva de dańos del artículo 2333 del Código Civil: a propósito de un fallo 
tancia que en materia ambiental, la normativa sectorial no contempla una acción de esta naturaleza. Sin embargo se ha señalado que el recurso de protección ambiental recogería una especie de acción popular ${ }^{47}$.

Pareciera lógico que el Estado representara este interés público o general en atención, entre otros factores, al artículo primero inciso cuarto de la Constitución ${ }^{48}$. Pero como ya hemos seńalado, al Consejo de Defensa del Estado le corresponde tutelar el interés del Estado y no el bien común ${ }^{49}$. Esta distinción es importante tenerla presente para determinar fehacientemente si existe representación de un interés supraindividual o no en su actuación.

Sin pretender agotar un tema de difícil conceptualización, consideramos un aporte al asunto en comento las palabras de Carvajal quien distingue claramente el bien común del bien público. El primero no se refiere al bien del Estado como organización sino al de todos ${ }^{50}$. Asimismo, De Lucchi señala que el interés público es "[...] el interés cuya gestión está encomendada, directa o indirectamente, a los poderes públicos. De entre los intereses que afectan a una comunidad de personas o a toda la sociedad, el Estado selecciona algunos en forma de intereses públicos y se constituye en su gestor y garante, pero los demás de esa naturaleza, que son los calificados intereses generales, se traducen, desde una perspectiva jurídico-subjetiva, en el interés en la mera legalidad, siendo sus titulares los ciudadanos por el hecho de serlo" 51 .

En consecuencia, el Consejo de Defensa del Estado no acciona en representación de un grupo de difícil o imposible determinación o de un grupo determinado de personas sino que en base a una ponderación de la situación ambiental con factores políticos, económicos, sociales, entre otros. Si bien puede ocurrir que intervenga ante perjuicios al entorno convergiendo con un interés difuso o incluso general, lo cierto es que también es factible que en virtud de un juicio político decida no accio-

reciente". Revista de Derecho de la Universidad de Concepción, Vol. 73 N²17-218, p. 319 y Corral Talciani, Hernán (2003). Lecciones de responsabilidad civil extracontractual. Santiago: Editorial Jurídica de Chile, p. 362.

47 Cfr, Peña (1997), 381.

48 Artículo 1 inciso cuarto Constitución: El Estado está al servicio de la persona humana y su finalidad es promover el bien común, para lo cual debe contribuir a crear las condiciones sociales que permitan a todos y a cada uno de los integrantes de la comunidad nacional su mayor realización espiritual y material posible, con pleno respeto a los derechos y garantías que esta Constitución establece. El destacado es nuestro.

49 El artículo 2 de la Ley Orgánica del Consejo de Defensa del Estado dispone que el Consejo de Defensa del Estado tiene por objeto, principalmente la defensa judicial de los intereses del Estado.

50 Cfr, Carvajal, Patricio Ignacio (2013) "Ciudadanía y bien común en la República”. Revista Chilena de Derecho, Vol. 40 N$^{\circ}$ 1. p. 376. Recomendamos ver la cita de Rosmini pues manifiesta que el bien público del Estado se encuentra orientada a la política de un gobierno, y el bien común es atemporal, pues se estructura en base a la justicia.

51 De Lucchi, Yolanda (2005) La tutela jurisdiccional civil de los intereses de consumidores $y$ usuarios. Madrid: Edisoffer s.l., p. 28. 
nar por un daño ambiental ${ }^{52}$. A mayor abundamiento, su dependencia del Poder Ejecutivo y la incoherencia lógica de tener que demandarse a sí mismo por un daño ambiental causado por un ente político redunda en que su legitimación activa responda a un interés público determinado del Estado, esto es, propio del gobierno y no a uno general o supraindividual.

\section{4) NECESIDAD DE RECONOCIMIENTO LEGAL DE LOS INTERESES Y DE NUEVOS LEGITIMADOS ACTIVOS}

Del análisis de la legislación podemos concluir que actualmente existe legitimación en materia ambiental solo para intereses individuales, tanto de particulares, las municipalidades y del Estado.

No existe tutela de intereses supraindividuales en nuestro ordenamiento ambiental. En otras palabras, la esfera de expectativas ambientales que un grupo determinado o indeterminado de personas pretenda hacer valer ante un tribunal de justicia actualmente no tiene reconocimiento legislativo y se encuentra carente de protección jurisdiccional. Lo mismo sucede con los intereses individuales homogéneos.

La necesidad de reconocimiento de nuevos cuerpos sociales que permitan superar estas falencias ha hecho que en materia del consumidor ${ }^{53}$, se contemple la posibilidad de iniciar el procedimiento colectivo mediante demanda presentada por una Asociación de Consumidores, cumpliendo con ciertos requisitos, tales como autorización de la asamblea y constitución a lo menos 6 meses previos a la presentación de la acción ${ }^{54}$. Asimismo, se legitima a un grupo de 50 personas afectadas para iniciar un proceso colectivo.

No vemos inconvenientes en que la legitimación entregada a estas Asociaciones en materia de consumidor pueda ser extrapolada a la legislación ambiental siempre que se tengan presentes las particularidades medio ambientales. La figura de Asociación Ecológica o de otras organizaciones no gubernamentales nos parece una acertada solución para tutelar intereses colectivos actualmente carentes de mecanismos de protección ${ }^{55}$.

\footnotetext{
52 Un ejemplo podría ser el de un daño ambiental que se manifiesta durante un año electoral en que de hacerse público el hecho podría atentar contra objetivos políticos o económicos.

Artículo 51 de la Ley $\mathrm{N}^{\circ} 19.496$.

Aguirrezabal (2010). 175-196.

Se manifiesta en idéntico sentido Delgado (2012) 64 cuando dichos organismos contengan en sus estatutos la defensa del medio ambiente. Recomendamos Verbic (2007) 187-191 para observar la importancia que los estatutos tienen en la limitación y control de la legitimación procesal de las asociaciones civiles.

Asimismo, dejamos constancia que nos parece del todo plausible que se consideren las comunidades de hecho como nuevos cuerpos sociales capaces de obtener la satisfacción de intereses colectivos ambientales, toda vez que se presentan como la forma natural de
} 
En el caso del grupo, también consideramos beneficiosos que se les otorgue legitimación activa para la reparación del ambiente pues ofrece tutela a los intereses individuales homogéneos.

Estimamos conveniente además la existencia de un organismo público autónomo, independiente de los poderes del Estado y cuya función sea demandar el daño ambiental. De esta forma el interés difuso podría recibir tutela judicial independiente de factores o presiones externas ${ }^{56}$.

La adecuada tutela de intereses supraindividuales ambientales implica su reconocimiento expreso en la normativa sectorial para que nuevos legitimados puedan accionar ${ }^{57}$. Sin embargo, pensamos que no se debe radicar la legitimación de estos en un solo ente determinado. Se requiere de un sistema de legitimación amplio capaz de albergar a todo interesado en participar del proceso. En el mismo sentido, Gutiérrez de Cabiedes e Hidalgo de Caviedes señala que dogmáticamente no existe consenso en relación al mejor mecanismo para la protección de intereses supraindividuales ${ }^{58}$. Concluye que "[...] la solución más optima vendrá dada por la adecuada combinación de las diversas posibilidades legitimadoras, compatibles en régimen de concurrencia y no de monopolio" 59 .

\section{5) COMENTARIOS AL NUEVO PROCEDIMIENTO POR DAÑO AMBIENTAL CONTENIDO EN LA LEY N² 20.600}

El medio ambiente es un bien jurídico colectivo que compromete variedad de intereses de naturaleza privada y supraindividual. El litisconsorcio del Código de Procedimiento Civil, el cual no fue diseñado para las demandas de masas, no logra dar solución a los problemas que la judicialización de un bien jurídico de estas características. La estructura de un nuevo proceso colectivo ambiental permite soslayar deficiencias que el

organización civil en sociedad. Sabemos que el problema de su reconocimiento radica en la acreditación de su existencia y en su adecuada representatividad. Encontramos apoyo para dicho planteamiento en el tratamiento que Bujosa (1995) 169-185 realiza sobre el grupo determinado no personalizado y el grupo indeterminado sin ente representativo organizado. En España existen las figuras del Ministerio Fiscal y el Defensor del Pueblo. Para un atingente comentario ver Gutiérrez de Cabiedes e Hidalgo de Caviedes (1999) 221-229.

57 El artículo 50 de la Ley $\mathrm{N}^{\circ} 19.496$ da cuenta que en materia de protección de los consumidores los intereses han sido legalmente definidos.

58 Gutiérrez de Cabiedes e Hidalgo de Caviedes (1999) 230. A modo de ejemplo, la Ley $\mathrm{N}^{\circ}$ 25.575, Ley General del Ambiente de Argentina, publicada en el Boletín Oficial el 28 de noviembre de 2002, regula expresamente el daño colectivo ambiental y dispone en su artículo 30 que son legitimados activos para demandar la reparación del daño ambiental el afectado, el Defensor del Pueblo, asociaciones no gubernamentales de defensa ambiental y el Estado nacional, provincial o municipal, sin perjuicio que el directamente afectado solicite la correspondiente indemnización.

59 Gutiérrez de Cabiedes e Hidalgo de Caviedes (1999) 230. 
antiguo procedimiento regulado en la LBGMA era incapaz de solucionar coherentemente, tal como en materia de notificaciones, publicidad, sentencias contradictorias, cosa juzgada, entre otros.

El día 28 de junio de 2012 se publicó la Ley $N^{\circ} 20.600$ que crea los Tribunales Ambientales. Constituye un nuevo esfuerzo legislativo para dotar al país de un moderno ordenamiento sectorial. Los Tribunales Ambientales son competentes para conocer, entre otras materias, de las acciones por daño ambiental. Resulta relevante comentar el nuevo procedimiento por daño ambiental contenido en el párrafo $4^{\circ}$, título III y el párrafo final de la ley $\mathrm{N}^{\circ} 20.600$.

El artículo 33 inciso primero dispone que el [...] procedimiento se iniciará por demanda o por medida prejudicial. En la demanda solo se podrá pedir la declaración de haberse producido daño ambiental por culpa o dolo del demandado y la condena de éste a repararlo materialmente de conformidad con lo dispuesto en el artículo 53 de la ley $N^{\circ}$ 19.300. Si la demanda no contiene estas menciones y todas las exigencias del artículo 254 del Código de Procedimiento Civil, el Tribunal ordenará complementarla dentro de quinto dia. Si asi no aconteciere, se tendrá por no presentada.

Esta disposición debe ser complementada con el artículo 45 del mismo cuerpo legal que señala: Será competente para conocer de la acción de indemnización de perjuicios por la producción de daño ambiental establecida en la sentencia del Tribunal Ambiental, el juzgado de letras en lo civil con competencia en el lugar donde se produjo el daño. - [...] El tribunal civil competente, al resolver sobre la indemnización de perjuicios se basará en el daño ambiental y la relación causal entre este y la acción del ofensor establecidas por el Tribunal Ambiental.

Del análisis de ambos artículos se desprende que el nuevo procedimiento por daños ambiental contempla un matiz particularmente relevante respecto de la ley $\mathrm{N}^{\circ}$ 19.300. En esta última ley se establecen las acciones derivadas del daño ambiental. La primera es la indemnizatoria y la segunda la ambiental. La legitimación activa de esta se observa en el artículo 53 y la de aquella en el artículo 54. Tradicionalmente se ha entendido que cada acción es independiente la una de la otra. Luego, hasta la dictación de la ley $N^{\circ} 20.600$ dichas acciones se podían deducir de forma separada, no existiendo vinculación directa entre ellas.

Sin embargo el ejercicio conjunto de ambas acciones siempre fue plausible. Quedaba a la discreción del accionante. En palabras de Romero "la acumulación inicial simple de acciones se produce cuando en una misma demanda se deducen varias acciones, para que sean tramitadas en un mismo procedimiento y sean resueltas en una misma sentencia" ${ }^{60}$. Esto es

60 Romero Seguel, Alejandro (2000). La acumulación inicial de acciones. Santiago: Editorial Jurídica ConoSur Ltda., p. 15. 
legítimo pues las acciones apuntan a resguardar bienes jurídicos distintos y por lo tanto no son excluyentes entre sí. La acción ambiental tiene por finalidad reponer el medio ambiente a una calidad similar a la que tenían con anterioridad al daño causado o, en caso de no ser ello posible, restablecer sus propiedades básicas. Por su parte, la acción de indemnización busca resarcir económicamente los daños causados a una persona que se ha visto ilícitamente afectado en sus derechos.

Asimismo, las acciones eran compatibles en función de los legitimados activos. Como vimos, en la acción de reparación los titulares pueden ser personas naturales o jurídicas, privadas o públicas, municipalidades o el Estado. A su vez, la acción de indemnización debe ser deducida exclusivamente por quien individualmente ha sufrido el daño. Esto responde básicamente a los distintos tipos de patrimonios por los que las acciones velan. En el primer caso se trata del medio ambiente, un patrimonio común, donde la pretensión objeto de la acción será vivir un medio ambiente adecuado. Por su parte, la segunda acción, responde a las necesidades de un patrimonio particular, donde el objeto de su ejercicio será resarcir económicamente los dańos a quien resultó personalmente afectado por el daño ambiental ${ }^{61}$.

A pesar de haber sido procedente su acumulación, esta quedaba al arbitrio de la parte demandante. En función de los artículos 33 y 45 de la ley $\mathrm{N}^{\circ} 20.600$ podemos concluir que actualmente dicha práctica es improcedente. Independiente de la naturaleza de la acción, sea ambiental o indemnizatoria, será menester solicitar ante el Tribunal Ambiental la declaración del daño ambiental y la condena a repararlo. Una vez obtenido, un Juzgado de Letras en lo Civil podrá conocer de la pretensión resarcitoria del demandante ${ }^{62}$.

$61 \quad$ Así por ejemplo, en el fallo pronunciado por el Juzgado de letras de Puerto Montt (Juzgado de letras de Puerto Montt, 19 de diciembre del año 2002, $R D C D E, \mathrm{~N}^{\circ} 16$, p. 138) en caso denominado Estado de Chile con Empresa Compañía Industrial Puerto Montt, donde el Consejo de Defensa del Estado, en representación de Estado de Chile, dedujo demanda de reparación de dańo ambiental y de indemnización de perjuicios por dańo ambiental en contra de Empresa Compañía Industrial Puerto Montt S. A. La acción ambiental se fundó en la destrucción de sitios arqueológicos; la indemnizatoria en razón que dichos sitios constituyen monumentos y en tal condición son de propiedad del Estado, el que resulta directamente afectado en su destrucción. En el considerando $31^{\circ}$ el tribunal de primera instancia manifiesta claramente que al presentarse la concurrencia de los prepuestos de la responsabilidad de la empresa, surge para esta la obligación de reparar o indemnizar. En atención al artículo tres de la Ley $\mathrm{N}^{\circ} 19.300$ concluye que existe una clara diferencia entre la responsabilidad civil y responsabilidad por un daño ambiental. En la primera, la obligación es de indemnizar y en la segunda es de reparar.

62 La decisión de disponer órganos distintos para el conocimiento de asuntos técnicos y resarcitorios no es nueva en nuestro ordenamiento, en especial en materias que comprometen gran cantidad de intereses, como son los asuntos ambientales y de libre competencia. Durante la tramitación de la ley se tuvo acuciosa consideración respecto del Tribunal de la Libre Competencia (en este sentido ver especialmente Historia de la ley $\mathrm{N}^{\circ} 20.600$, p. 704). 
Luego, entre otras diferencias con el antiguo y derogado procedimiento sumario por dańo ambiental, con la entrada en vigencia del segundo Tribunal Ambiental, acreditar el daño al entorno será requisito inevitable tanto para el ejercicio de una acción ambiental como indemnizatoria. En otras palabras para demandar la indemnización primero deberá existir una sentencia estimatoria de la acción de reparación ambiental, máxime cuando el artículo 46 señala que en sede civil el tribunal deberá basarse en el daño ambiental y la relación causal entre este y la acción del ofensor establecidas por el Tribunal Ambiental para resolver la indemnización de perjuicios.

Este cambio de paradigma procesal en materia ambiental viene a responder a un problema jurídico que nuestra doctrina ya había advertido, esto es, el enriquecimiento sin causa del directamente afectado por el daño ambiental. Barros, en ocasión de la ley $\mathrm{N}^{\circ} 19.300$ hoy modificada, manifestó que entre ambas acciones "el límite de esta concurrencia está dado, con todo, por la eventual superposición de sus objetos: la reparación en naturaleza suele constituir por sí misma un sustituto de la indemnización, porque su efecto es precisamente neutralizar el daño" 63 .

Por su parte Valenzuela ilustró la situación en el siguiente ejemplo. El agricultor dueño de un predio es afectado por un dańo causado al suelo de su propiedad por sustancias sulfurosas provenientes de una refinería minera, pudiendo demandar indemnización de perjuicios por daño emergente y lucro cesante. En caso de una sentencia estimatoria, nada lo obliga a invertir ese dinero en las medidas de reparación de su propiedad. Por lo tanto, posteriormente podría deducir la acción ambiental y en caso de obtener una sentencia favorable en el juicio, obligar al contaminante a reparar su predio; el agricultor se vería doblemente recompensado, incrementando injustamente su patrimonio ${ }^{64}$.

Nosotros ya nos habíamos pronunciado respecto de una posible solución al problema ${ }^{65}$, pero la ley 20.600 zanjó la discusión. Si bien ambas

Esto explica la similitud en la tramitación de las acciones indemnizatorias tanto en materia ambiental como de libre competencia. El artículo 30 del texto refundido, coordinado y sistematizado del DL N 211 de 1973, publicado en el Diario Oficial de 7 de marzo de 2005, sostiene que la acción de indemnización de perjuicios a que haya lugar, con motivo de la dictación por el Tribunal de Defensa de la Libre Competencia de una sentencia definitiva ejecutoriada, se interpondrá ante el tribunal civil competente de conformidad a las reglas generales, $y$ se tramitará de acuerdo al procedimiento sumario, establecido en el Libro III del Título XI del Código de Procedimiento Civil.- El tribunal civil competente, al resolver sobre la indemnización de perjuicios, fundará su fallo en las conductas, hechos y calificación jurídica de los mismos, establecidos en la sentencia del Tribunal de Defensa de la Libre Competencia, dictada con motivo de la aplicación de la presente ley.

63 Barros (2006) 809.

64 Cfr, Valenzuela (1998) 69-70.

65 En Cfr, Tisné (2010) 103-104 propusimos que ante el acaecimiento de un daño ambiental, el afectado que estimara conveniente demandar una indemnización, lo hiciera siempre en 
acciones continúan estando previstas de forma independiente en la ley $\mathrm{N}^{\circ}$ 19.300 , actualmente su tramitación exige al directamente afectado ejercer la acción ambiental para solicitar el resarcimiento del daño. Además la acción indemnizatoria deberá tramitarse posteriormente en sede civil en un procedimiento especial ${ }^{66}$.

Teniendo presente las características del nuevo procedimiento por dańo ambiental, resulta menester distinguir las fases comunes de las acciones. La acción ambiental pasa a estar subsumida en la indemnizatoria. Se puede decir que existe una máxima procesal, esta es, toda acción indemnizatoria en virtud de un daño ambiental requiere ejercer previamente la de reparación, pero aquella no requiere del ejercicio de esta.

Una sutil modificación al nuevo procedimiento que hemos comentado permitiría fraccionarlo en dos fases lo que generaría ostensibles beneficios procesales. La primera tendría por finalidad probar el daño ambiental y condenar a su reparación. La segunda, solicitar la indemnización de perjuicios.

subsidio de la acción ambiental. En este sentido, el tribunal velaría en primer lugar por los componentes ambientales transgredidos y con posterioridad por el perjuicio individual. Planteamos que en función del antiguo procedimiento sumario por daño ambiental, se debía distinguir entre el tipo de sentencia pronunciada por el tribunal. De ser estimatoria, el juez tendría en consideración la resolución previa para determinar el monto efectivo que el demandante debe percibir por concepto de daño emergente, impidiendo que se genere el enriquecimiento injusto. De ser desestimatoria, el juez resolvería respecto de la procedencia de la indemnización solicitada por del demandante a través de un procedimiento de lato conocimiento en función de las normas de responsabilidad extracontractual del Código Civil pues se habría probado con anterioridad la inexistencia de un dańo ambiental.

66 Hacemos presente que existió una sentencia disidente a la otrora regla general sobre la procedencia de la acumulación de acciones que consideró improcedente entablar las acciones conjuntamente. Para sostener su decisión, los jueces se basaron en el procedimiento aplicable a las acciones. Sin perjuicio de la existencia del artículo 61 en la LBGMA (hoy derogado) que disponía que la tramitación de las acciones que emanan de un dańo ambiental se tramitarían a través de un procedimiento sumario, el tribunal estimó que la acción indemnizatoria debía tramitarse a través de un juicio ordinario. Esta sentencia que parecía equívoca en relación al antiguo procedimiento por dańo ambiental, hoy parece acercarse más a lo pretendido por el legislador en la ley $\mathrm{N}^{\circ}$ 20.600. En el caso en comento (Corte Suprema, 25 de abril de 2001, rol N³404-2000) caratulado Sociedad Handels Und Finaz A.G. Chile S.A. con Sociedad Chilquinta, el Tribunal de Letras de La Calera en el considerando $3^{\circ}$ señaló "que no existe regla expresa en la mencionada ley que otorgue a los perjudicados directamente con el daño ambiental acciones indemnizatorias en el mismo procedimiento sumario, de manera que respecto de esas acciones debe estarse a lo dispuesto en las reglas generales, siendo improcedente la tramitación conjunta de ambas acciones en el mismo procedimiento". La Corte de Apelaciones de Valparaíso señaló en el considerando $1^{\circ}$ "que conforme a la historia fidedigna de la ley [...] fluye que entre las finalidades superiores del mencionado cuerpo legal se encuentra en forma principal la reparación del daño causado al medio ambiente, como el castigo a los culpables". Continuó en el considerando $2^{\circ}$ explicando que la ley en cuestión tiene por objeto la rápida restauración del medio ambiente menoscabado "lo cual no obsta al ejercicio de la acción indemnizatoria ordinaria por el directamente afectado pero a través del procedimiento ordinario". La Corte Suprema tuvo por desistido el recurso de casación en el fondo deducido contra la sentencia de segunda instancia. 
La primera fase abre la puerta para que los intereses estudiados puedan acceder a la tutela jurisdiccional mediante una representación adecuada. Con la acreditación del daño ambiental como primer obstáculo para alcanzar las pretensiones solicitadas, acciones colectivas en defensa de intereses individuales homogéneos, colectivos o difusos, adquieren inusitada relevancia. A la luz de la nueva legislación, los beneficios de una fase con características colectivas, al menos para probar el daño y solicitar su reparación, subsanarían las dificultades procesales propias de los daños ambientales.

A mayor abundamiento, si actualmente se exige al directamente afectado accionar por la reparación como requisito previo para una indemnización, pareciera contraproducente no admitir nuevos legitimados activos. El particular, como hemos señalado, se enfrentará a cortapisas fácticas y psicológicas que desincentivarán su intervención judicial. Admitir la accionabilidad de nuevos entes que representen interés supraindividuales o individuales homogéneos permite que el interés ambiental sea satisfecho con mayor diligencia y premura, evitando que el particular afectado permanezca en una posición desfavorable en ocasión de una litis ambiental. El presente planteamiento permite que el interés colectivo que genera el daño a un patrimonio común, como es el ambiental, sea protegido por el cúmulo de interesados. Una vez satisfecha aquella pretensión colectiva, el particular afectado deberá velar por su patrimonio personal en un procedimiento resarcitorio. Es una fórmula en que los intereses confluyen y se benefician mutuamente, tanto para las pretensiones colectivas como individuales.

Esta idea de fraccionar el procedimiento no es nueva en nuestro ordenamiento nacional. En la protección de los derechos de los consumidores, que también importa un bien jurídico colectivo, el procedimiento por infracción al interés colectivo y difuso (artículo 51 de la ley $\left.\mathrm{N}^{\circ} 19.496.\right)$ supone distinguir "[...] dos etapas: una de declaración de existencia de la infracción a las normas que protegen los intereses supraindividuales y en que se declara admisible o inadmisible la acción para su defensa, y una segunda etapa, de carácter reparatorio, la que solo se alcanza una vez que se ha declarado la existencia de la conducta infraccional y el derecho del grupo de consumidores a ser indemnizado" 67 . La relación existente en materia de consumidores y medio ambiente ha sido acusada por los autores ${ }^{68}$.

$67 \quad$ Aguirrezabal (2006) 158.

68 Un ejemplo es Vigurí, Agustín (1999). "Las acciones en defensa de intereses colectivos en el ámbito del medio ambiente”. En Felipe González y Felipe Viveros (editores). Cuadernos de Análisis Jurídicos. Defensa jurídica del interés público. Enseñanza, estrategias, experiencias. Santiago: Escuela de Derecho Universidad Diego Portales, p. 153-154 quien señala que "a diferencia de los intereses colectivos, cuyo contenido es supraindividual, con un centro de referencia no ocasional, sino constituido por un ente asociativo (bien sea un órgano público, una asociación sindical o un colegio profesional), los intereses difusos aparecen correlativos 
De este modo la sentencia que declare acaecido el daño ambiental y condene a su reparación beneficiará al menos a todos aquellos que hayan sido debidamente representados en el juicio. Hacemos dicha salvedad pues el efecto de cosa juzgada en materia de procesos colectivos no es pacífico en la dogmática y ha promovido variedad de pronunciamientos en el derecho comparado ${ }^{69}$. En materia de consumidor, el propio legislador determinó que por regla general la sentencia ejecutoriada que declare la responsabilidad del o los demandados producirá efectos erga omnes ${ }^{70}$. De no existir una disposición de estas características en la normativa sectorial ambiental, el efecto de la sentencia debería ser el tradicional, esto es, relativo a las partes que participan del proceso conforme al artículo 3 inciso segundo del Código Civil.

Sabemos que esta postura puede encontrar detractores porque supone que cada persona que pretenda una indemnización y que no haya participado como parte o tercero coadyuvante en un juicio ambiental debe iniciar uno a través de una demanda o medida prejudicial, solicitando nuevamente la declaración del daño y su reparación. Esto puede generar multiplicidad de juicios, sentencias contradictorias y llevar incluso a absurdos. Las medidas de reparación del ambiente pueden ser determinadas en una sentencia judicial, a menos que existan nuevos antecedentes, independiente del tiempo que demore la reparación. Puede ocurrir que se condene a reparar el dańo en una sentencia dictada al ańo de su manifestación evidente sin perjuicio que la acción de indemnización sea ejercida al quinto ańo conforme a los artículos 46 inciso final de la ley $\mathrm{N}^{\circ} 20.600$ y 63 de la ley $\mathrm{N}^{\circ} 19.300$. En este caso ¿Cuál es la reparación que se solicitará? Sería un trámite innecesario para cumplir la formalidad que exige la legislación para obtener la real pretensión del demandante, esto es, la indemnizatoria. A pesar de prever dicha situación, entendemos que a falta de una norma especial que expresamente señale un efecto distinto de la

a formaciones sociales aún en fase de toma de conciencia, cuya individualización se realiza a través de la relevancia de una lesión verificada en perjuicio de una pluralidad de individuos que se asocian para su defensa (el dańo es su único punto en común, y su vinculación perdurará solo mientras este subsista). En el momento presente, el medio ambiente se encuadra entre este tipo de intereses, junto a la problemática de consumidores y usuarios".

69 Entre estos encontramos los que abogan por la eficacia relativa de la sentencia, el efecto ultra partes o la cosa juzgada secumdum eventum litis. Conforme a Aguirrezabal, Maite (2010). "La extensión de los efectos de la sentencia dictada en procesos colectivos promovidos para la defensa de los intereses colectivos y difusos de consumidores y usuarios: régimen en la ley chilena de protección del consumidor". Revista Ius et Praxis, Vol. $16 \mathrm{~N}^{\circ}$ 1, pp. 102-105, el primero dice relación con el efecto ordinario de la sentencia en cuanto relativo únicamente a las partes del proceso. En relación al efecto ultra partes, se entiende que la resolución afectará a toda persona que tenga interés en el asunto, haya sido parte del proceso o no. Finalmente el efecto secumdum eventum litis dice relación con que el efecto de cosa juzgada solo afectará a las partes del juicio si la sentencia desestima las pretensiones, en caso contrario, beneficiará a todos los interesados.

Artículo 54 de la Ley de Protección al Consumidor. 
sentencia en sede ambiental, esta generará un efecto relativo entre las partes. Si se pretende que la sentencia tenga un alcance disímil, será labor del legislador establecerlo de ese modo.

En suma, una vez que en la primera fase sean satisfechos los intereses comprometidos mediante la obtención de una declaración judicial del daño ambiental y la condena a su reparación, la indivisibilidad de los intereses supraindividuales ya no se presenta como un hecho relevante, siendo en una segunda fase, que la individualidad de los afectados se torna significativa para solicitar las correspondientes indemnizaciones producto del daño ambiental en el Juzgado Civil competente.

\section{CONCLUSIONES}

Nuestro ordenamiento no ofrece una idónea tutela a los intereses ambientales. El sistema de responsabilidad por dańos al ambiente continúa configurándose bajo el velo de la lógica individual decimonónica, impidiendo superar la problemática fáctica, psicológica y cultural que actualmente desincentiva la promoción judicial de los intereses comprometidos.

Consideramos que el reconocimiento legal de los distintos legitimados cuyos intereses ambientales se comprometen en ocasión de un daño $\mathrm{y}$, además, de un proceso que admita su intervención procesal es la senda adecuada para la tutela de los intereses involucrados. Luego, nos parece conveniente que en el nuevo procedimiento por daño ambiental contenido en la ley $\mathrm{N}^{\circ} 20.600$ se distinga entre una fase inicial, en que se procure la declaración del daño y la condena a su reparación en sede ambiental, y otra posterior para resarcir los daños individuales en sede civil.

La primera fase tendría por objeto ofrecer un debido acceso a la justicia a aquellos nuevos legitimados activos que representen los intereses ambientales. Su aplicación soslayará en buena medida las dificultades e inconveniente asociados a la prueba del daño y promovería una protección del medio ambiente compatible y recíprocamente ventajosa con las pretensiones indemnizatorias del directamente afectado.

\section{BIBLIOGRAFÍA}

- Aguirrezabal, Maite (2006). "Algunas precisiones en torno a los intereses supraindividuales (colectivos y difusos)". Revista Chilena de Derecho, Vol. $33 \mathrm{~N}^{\circ} 1$.

- Aguirrezabal, Maite (2006). "El procedimiento para la defensa de intereses colectivos y difusos de consumidores y usuarios en la Ley 19.496". Cuadernos de Extensión Juridica (U. de los Andes), N 12. 
- Aguirrezabal, Maite (2010). "El control de la representatividad adecuada de las asociaciones de consumidores en el ejercicio de las acciones colectivas". Revista de Derecho Universidad Austral de Chile, Vol. $23 \mathrm{~N}^{\circ} 2$.

- Aguirrezabal, Maite (2010). "La extensión de los efectos de la sentencia dictada en procesos colectivos promovidos para la defensa de los intereses colectivos y difusos de consumidores y usuarios: régimen en la ley chilena de protección del consumidor". Revista Ius et Praxis, Vol. $16 \mathrm{~N}^{\circ} 1$.

- Alessandri, Arturo (2005) De la responsabilidad extracontractual en el derecho civil chileno. Santiago: Editorial Jurídica de Chile.

- Amunátegui Pereló, Carlos Felipe (2012). "Las relaciones de vecindad y la teoría de las inmisiones en el Código Civil". Revista de Derecho de la Pontificia Universidad Católica de Valparaíso, Vol. 38 $\mathrm{N}^{\circ} 1$, p. 115

- Barros, Enrique (1998). "Responsabilidad civil en materia de medio ambiente". Derecho del Medio Ambiente Congreso Internacional. Santiago: LexisNexis.

- Barros, Enrique (2006) Tratado de responsabilidad extracontractual. Santiago: Editorial Jurídica de Chile.

- Bordalí, Andrés (2004) Tutela jurisdiccional del medio ambiente. Santiago: Editorial Fallos del Mes.

- Bujosa, Lorenzo (1995) La protección jurisdiccional de los intereses de grupo. Barcelona: J.M. Bosch editor.

- Brañes, Raúl (2000) Manual de derecho ambiental mexicano. 2a ed. México, D. F.: Fundación Mexicana para la Educación Ambiental Fondo de Cultura Económica.

- Carvajal, Patricio Ignacio (2013) "Ciudadanía y bien común en la República”. Revista Chilena de Derecho, Vol. 40 N 1.

- Corral, Hernán (1996). "Daño ambiental y responsabilidad civil del empresario en la Ley de Bases Generales del Medio Ambiente". Revista Chilena de Derecho, Vol. $23 \mathrm{~N}^{\circ} 1$.

- Corral Talciani, Hernán (2003). Lecciones de responsabilidad civil extracontractual. Santiago: Editorial Jurídica de Chile.

- De Lucchi, Yolanda (2005) La tutela jurisdiccional civil de los intereses de consumidores y usuarios, Madrid: Edisoffer s.l.

- Delgado, Verónica (2012) "La responsabilidad civil extracontractual por daño ambiental causado en la construcción u operación de las carreteras". Revista de Derecho (Valdivia), Vol. $25 \mathrm{~N}^{\circ} 1$.

- Delgado Schneider, Verónica Pía (2005). "La protección del medio ambiente a través de las acciones populares del artículo 948 del Código Civil de Andrés Bello: un estudio históricocomparativo". En María Dora Martinic G., y Mauricio Tapia R. (dirección). Sesquicentenario del Código Civil de Andrés Bello. 
Pasado, presente y futuro de la codificación. Santiago: LexisNexis, t. II.

- Diez Schwerter, José Luis (2005). "Notas sobre la acción preventiva de daños del artículo 2333 del Código Civil: a propósito de un fallo reciente". Revista de Derecho de la Universidad de Concepción, Vol. $73 \mathrm{~N}^{\circ}$ 217-218.

- Garrido, Lidia (1993) Los daños colectivos y la reparación. Buenos Aires: Editorial Universidad.

- Gidi, Antonio (2003). "Derechos difusos, colectivos e individuales homogéneos". En Gidi, Antonio y Ferrer Mac-Gregor, Eduardo (editores). En La tutela de los derechos difusos, colectivos e individuales homogéneos. Hacia un Código Modelo para Iberoamérica. México: Editorial Porrúa.

- Gidi, Antonio (2003). "El concepto de acción colectiva”. En Gidi, Antonio y Ferrer Mac-Gregor, Eduardo (editores). La tutela de los derechos difusos, colectivos e individuales homogéneos. Hacia un Código Modelo para Iberoamérica. México: Editorial Porrúa.

- Gidi, Antonio (2003). "Legitimación para demandar en las acciones colectivas". En Gidi, Antonio y Ferrer Mac-Gregor, Eduardo (editores). La tutela de los derechos difusos, colectivos e individuales homogéneos. México: Editorial Porrúa.

- González Cruz, Francisco Javier y Acevedo Ferrer, Santiago (2013). "Revisión crítica del estatuto de responsabilidad civil por daños nucleares en Chile". En Revista Chilena de Derecho, Vol. 40 N$^{\circ} 1$.

- Gutiérrez de Cabiedes e Hidalgo de Caviedes, Pablo (1999) La tutela jurisdiccional de los intereses supraindividuales: colectivos $y$ difusos. Navarra: Editorial Arazandi.

- Moreno, Pablo (2002) El interés de grupo como interés tutelado. Bogotá: Universidad Externado de Colombia.

- Peña González, Carlos (1997). "Las acciones de interés público en el ordenamiento jurídico chileno. Antecedentes dogmáticos y conceptuales". En Felipe González Morales (editor). Cuadernos de análisis jurídico. Serie publicaciones especiales. Las acciones de interés público. Argentina, Chile, Colombia y Perú. Santiago: Escuela de Derecho Universidad Diego Portales, $N^{\circ} 7$.

- PÉrez, Lorenzo (2002) La tutela judicial de los intereses ambientales (Estudio especifico de la legitimación <<difusa >> en el proceso contencioso-administrativo). Valladolid: Editorial Lex Nova.

- Roca Juan, Juan (1986): "Sobre el deber general de respeto a la persona (derecho civil y medio ambiente)". Anuario de Derecho Civil, vol. $39 \mathrm{~N}^{\circ} 3$.

- Romero, Alejandro. (2006) Curso de derecho procesal civil. La acción y la protección de los derechos. Santiago: Editorial Jurídica de Chile. t. I. 
- Romero Seguel, Alejandro (2000). La acumulación inicial de acciones. Santiago: Editorial Jurídica ConoSur Ltda., p. 15.

- Silva, Hernán (1993). "La protección del ambiente en el derecho constitucional y penal”. Revista Chilena de Derecho, Vol. 20 N$^{\circ} 2-3$.

- Tisné NiemanN, Jorge (2012). "Algunas particularidades en torno al derecho de acción ambiental en la ley número 20.600". En Revista de Derecho de la Universidad de Concepción, Vol. 80 N²31-232.

- Tisné Niemann, Jorge Bertrand (2010) Acción de reparación Ambiental. Aspectos procesales relevantes. Tesis para optar al grado de Licenciado en Derecho. Universidad de los Andes.

- Toledo, Fernando (1996) Ley sobre Bases Generales del Medio Ambiente: Ley Número 19.300, historia fidedigna y concordancias internas. Santiago: CONAMA.

- Valenzuela, Rafael (1998). "La Responsabilidad Civil por Daño Ambiental". En Derecho del Medio Ambiente Congreso Internacional. Santiago: LexisNexis.

- Valls, Mario (2001) Manual de Derecho Ambiental. Buenos Aires: Ugermer Editor.

- Verbic, Francisco (2007) Procesos Colectivos. Buenos Aires: Editorial Astrea.

- Vigurí, Agustín (1999). "Las acciones en defensa de intereses colectivos en el ámbito del medio ambiente". En Felipe González y Felipe Viveros (editores). Cuadernos de Análisis Jurídicos. Defensa jurídica del interés público. Enseñanza, estrategias, experiencias. Santiago: Escuela de Derecho Universidad Diego Portales. 